\title{
Joy and Calm: How an Evolutionary Functional Model of Affect Regulation Informs Positive Emotions in Nature
}

\author{
Miles Richardson $^{1} \cdot$ Kirsten McEwan $^{2} \cdot$ Frances Maratos $^{1} \cdot$ David Sheffield $^{1}$
}

Published online: 23 August 2016

(C) Springer International Publishing 2016

\begin{abstract}
Key theories of the human need for nature take an evolutionary perspective, and many of the mental well-being benefits of nature relate to positive affect. As affect has a physiological basis, it is important to consider these benefits alongside regulatory processes. However, research into nature and positive affect tends not to consider affect regulation and the neurophysiology of emotion. This brief systematic review and meta-analysis presents evidence to support the use of an existing evolutionary functional model of affect regulation (the three circle model of emotion) that provides a tripartite framework in which to consider the mental well-being benefits of nature and to guide nature-based well-being interventions. The model outlines drive, contentment and threat dimensions of affect regulation based on a review of the emotion regulation literature. The model has been used previously for understanding mental well-being, delivering successful mental health-care interventions and providing directions for future research. Finally, the three circle model is easily understood in the context of our everyday lives, providing an accessible physiological-based narrative to help explain the benefits of nature.
\end{abstract}

Keywords Affect regulation · Positive affect .

Neurophysiology of emotion $\cdot$ Nature $\cdot$ Well-being

Biophilia takes an evolutionary perspective that humans have a biologically based innate need to affiliate with life in the

Miles Richardson

m.richardson@derby.ac.uk

1 University of Derby, Kedleston Road, Derby DE22 1GB, UK

2 Cardiff University, Heath Park, Cardiff CF14 4YS, UK natural world and to recognise and seek out the resources the natural world provides (e.g. food, water, shelter) (Wilson 1984; Kellert 1993). The human brain is also a product of evolution, and difficulties including mental health can arise when we become ignorant of our origins as part of nature (Wilson 1992). Following the functional-evolutionary perspective of Ulrich (1983), affective emotions are often considered in research concerning our connection to nature, and the benefits people derive from nature. Such work often focusses on positive affect (e.g. McMahan and Estes 2015) but does not tend to consider an evolutionary functional view of affect regulation and the neurophysiology of emotion. As our connection to and the benefits of nature are affective, and affect has a physiological basis, it is important to consider the wellbeing benefits of nature within a model of affect regulation. This review considers the emotion regulation literature before presenting evidence from empirical work in natural environments to support the application of an existing evolutionary functional model of affect regulation, namely the three circle model of emotion (Gilbert 2005), to this domain. This model provides a useful framework in which to consider positive affect and the mental well-being benefits of nature.

\section{Neurophysiology of Emotion}

Affect is the constant companion of sensation, with feelings, rather than thoughts, coming first when encountering nature; Ulrich's functional-evolutionary perspective suggests that encounters with nature can induce wakeful relaxation and positive emotional reactions (Ulrich 1983). Emotions provide the impetus for action and motivation, impacting the body in a manner that cognition alone cannot (Gilbert 2014). Emotions have a biological basis and analysis of emotion should not exclude regulatory processes; emotions and their regulation 
should be considered as one (Kappas 2011). For well-being, these emotions need to be balanced as affect regulation systems control our heart and muscles and the way our brain functions in order to achieve balance (Kappas 2011).

Taking an evolutionary perspective, origins of the scientific approach to emotion are largely credited to Darwin (1872) and the idea that emotions have evolved as solutions to nature that promote survival. Termed 'serviceable association habits', Darwin suggested that emotions and their expressions evolved because they are reliable antecedents of particular behaviours, with Frijda (1987) suggesting a relatively small set of such action tendencies. According to Frijda, these action tendencies allow us to establish, maintain or disrupt a relationship with the environment. This is perhaps not too dissimilar to the arguments of Gray (1982) who suggested that three fundamental emotion systems exist in the brain to enable situation-specific responses (primarily to resolve anxiety): a fight or flight system (F/FLS), a behavioural activation system (BAS) and a behavioural inhibition system (BIS). Based upon research in rats, Gray suggested a number of brain circuits and roles involved in these different systems. Albeit simplified, the F/FLS system (amygdala, hypothalamus, central grey) serves to enable defensive reactions, the BAS (basal ganglia, dopaminergic tracts) to enable approach to signals of reward and non-punishment and the BIS (septo-hippocampal circuits) can be thought of as a mediator when conflict arises in situations of approach-avoidance conflict. At the level of the rat, the latter could be considered conflict between the presence of food (appetitive and rewarding) and the scent of a cat (predatory and feared).

Of note, much research has focused on the F/FLS system drawing, for example, from the early work of Papez (1937) and MacLean (1949). Emerging from such literature, great emphasis has been given to the limbic system and regions such as the amygdala in emotion and threat processing. Largely based upon the research of LeDoux $(1998,2014)$, the amygdala is well-established as playing a key role in the processing of emotional information, regulating emotional responses and controlling fear reactions in a range of species (see for example Fox et al. 2015; Phelps and Ledoux 2005 for reviews). Indeed, much recent research still supports the notion that a phylogenetically old subcortical pathway provides rapid, but coarse, threat-related signals in humans via the amygdala (Méndez-Bértolo et al. 2016; Maratos et al. 2009). However, this approach is not without criticism, and Pessoa (2014) suggests that given its rich connectivity, the amygdala is arguably a processing hub belonging to a minimum of at least three networks pertaining to visual processing, autonomic awareness and the generation of bodily states, and a values network in which the value of a current state and future reward is evaluated relatively. This values network arguably arises given the rich connectivity between the amygdala and almost all regions of the prefrontal cortex (PFC) (Averbeck and Seo
2008). Certainly, the PFC (commonly referred to as the 'seat of reasoning') is now well-established in emotion regulation processes (see Ochsner et al. 2012 for review), with disrupted connectivity between limbic and prefrontal brain regions implicated in a number of affective disorders such as anxiety (Etkin 2009) and depression (de Almeida et al. 2009).

A different, but no less valid, perspective to approach emotion and emotion regulation is via identification of the neurochemical systems that influence emotional responding. Here, prominence should be given to Panksepp (1998a, b) whose research gave rise to the importance of different neurotransmitters for particular affective systems/states. Again applying a tripartite model or the notion of a 'triune' brain (MacLean 1990), Panksepp proposed that affective processes can be divided into reflective affects such as pain or pleasure (brain stem regions), grade A emotions such as fear or joy (mid brain regions) and higher sentiments such as shame, guilt, empathy, etc. (frontal cortex). Importantly, however, Panksepp noted that all such emotions were subserved by a number of neurotransmitters - from serotonin and noradrenaline (norepinephrine) more generally across all levels, to dopamine, oxytocin and opioids more specifically involved in seeking, reward, play/pleasure and care.

For example, dopamine is key in reward processes (Bressan and Crippa 2005), with dopamine-producing neurons in the substantia nigra connecting to the basal ganglia. In a second pathway, dopamine-producing neurons in the ventral tegmental area (VTA) connect with the hypothalamus and basal ganglia (collectively named the 'pleasure centre' by Olds 1956), as well as the amygdala and frontal regions. Oxytocin has been suggested to be key in maternal care and romantic care, with receptors for oxytocin, located in high numbers, for example, in the central nucleus of the amygdala. Additionally, in rats, blocking receptors for oxytocin in the VTA leads to the blocking of maternal behaviours (Pedersen et al. 1994), and in prairie voles, the blocking of oxytocin leads to decreased pair bonding and increased promiscuity (Cho et al. 1999). Human research also appears to demonstrate the central role of oxytocin in affiliative relationships spanning kin, romantic bonding and trust (Graustella and MacLeod 2012), but this research is not without its critics (Nave et al. 2015). Finally, opioids are well-established in the relief of pain, with research suggesting that both opioid and dopamine systems are important in modulating both pain and pleasure (Leknes and Tracey 2008).

Gilbert $(2005,2014)$ attempted to assimilate such research from these varied approaches to emotion regulation into an accessible model. It is of note that whilst this is not the only recent model of emotion regulation (see for example Etkin et al. 2015; Lindquist et al. 2012), the approach taken by Gilbert is to draw literature from beyond the neuroimaging literature as well as place greater emphasis on positive emotions in any such model. In doing so, Gilbert (2014) outlines a 
'three circle model of emotion' and affect regulation (see Fig. 1). This model not only draws from existing theory and literature such as that above, but also takes into account advances made with regard to our understanding of affiliative and positive emotions with respect to reward pathways, dopamine and oxytocin (see also Depue and Morrone-Strupinsky 2005 for review), as well as research into the balance between the sympathetic and parasympathetic nervous system by Porges $(1995,2007,2009)$. The three circles of this model represent drive, threat and contentment and are easily understood in the context of our everyday lives. Drive - resource focus, wanting, pursuing, achieving and consuming - is associated with feelings of excitement, joy and pleasure and notably linked to dopaminergic systems. The function of this system is to drive us towards resources and rewards. Contentment - safeness, connection and affiliative focus-is associated with feelings of contentment, safeness, calm and notably linked to oxytocin and opiate systems. The function of this system is to 'turn-off or tone-down' drive and threat systems and to restore energy. This system also evolved to enable attachment and functions to provide a calming soothing process when affiliative signals are present so that individuals can engage with affiliation and attachment behaviours. Threatanxiety focus, protection, safety seeking, activating and inhibiting - is associated with feelings of anxiety, anger and sadness and notably linked to adrenaline, as well as cortisol and also noradrenaline. The function of this system is defensive and protective, to keep us alert to threats and to seek safety.

When considering responses to natural environments, Ulrich (1983) noted that drive and contentment can be seen to correspond with positive and relaxing reactions. From such a perspective, the balance between drive and contentment can also be compared to the long-standing account of two phases of positive states: appetitive activity 'doing' and consummatory response 'being' (Tinbergen 1951). Once a goal has been achieved (e.g. a resource such as food has been obtained), drive systems need to be 'turned off or toned down' (downregulated) to balance energy expenditure and provide positive affect in the form of contentment. This is not dissimilar to the approach of Gray (1982), but in the nature example described here, the contentment system is seen as affect-regulating (Depue and Morrone-Strupinsky 2005) although, comparatively, as distinct from the drive system and feelings of excitement (Gilbert et al. 2008).

This stated that it is important to note that the above brief description of the model in terms of emotions to nature is an accessible simplification. Presented in such a manner allows for the quick understanding, explanation and framing of research findings related to how nature affects our mood states and our physiology, and also acts as an emotional regulator. Of note, in reference to the three circle model (i.e. Gilbert 2014), the model is more complex and dynamic than as described

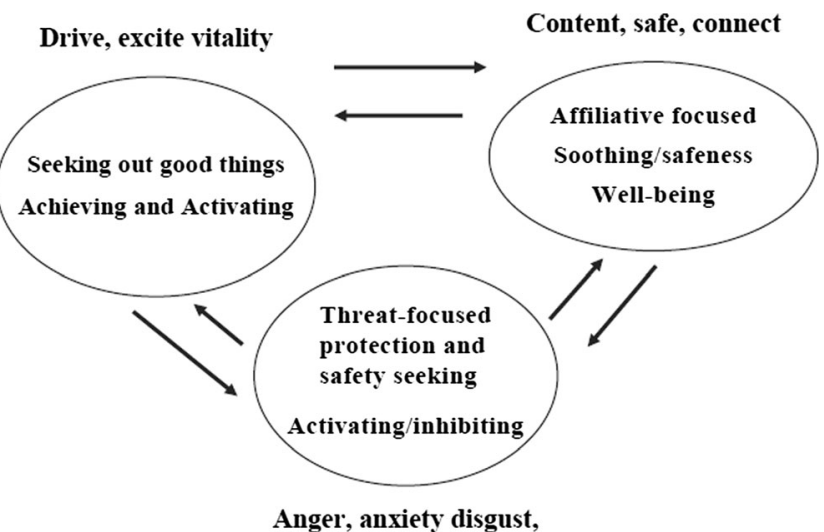

Fig. 1 Three types of affect regulation system. From Gilbert (2009a), The Compassionate Mind. With permission from Constable-Robinson

above with each of the three systems regulating each other to produce blended affects. For example, affiliation is not just linked with the contentment system, it can be linked to the drive system (e.g. excitement about a social event or relationship) or the threat system (e.g. anxiety when a loved one becomes ill), just as both opioids and dopamine are linked to pleasure and pain.

Importantly, it has recently been argued that evolutionary aspects of human connection to nature have modern clinical relevancy and nature should be part of established mental health care (Mantler and Logan 2015). The three circle model of affect regulation presented provides a foundation for compassion-focused therapy (Gilbert 2009b, 2014), thus showing its utility for improving the understanding of mental well-being and delivering successful mental health-care interventions. Certainly, the three circle model is used successfully in both clinical and non-clinical settings alike to explain the 'tricky brain' scenario and how the complexity of evolved and dynamic brain systems interplays with our physical and mental health. Its accessibility, for example, has led to its appearance not only in research papers and training manuals but in popular web forums such as 'Netmums', as a model to improve health and happiness (Netmums 2016). This same model of affect regulation can be applied to explain the benefits derived from nature (e.g. promotion of soothing affect) and to guide interventions (e.g. ecotherapy) which aim to increase well-being through our connection with nature.

\section{Considering Types of Positive Affect}

Despite the models of affect regulation presented above (most notably the three circle model), and although Ulrich (1983) outlined two types of positive affect (wakeful relaxation and positive emotional reactions to nature), the majority of studies into the benefits of nature, and a connection to nature, have focused on and found increases in a single dimension of positive affect (see McMahan and Estes 2015 for review), without 
considering specific types of positive affect or regulatory processes. Howell and Passmore (2013) note that research into positive affect and nature has had some mixed results and this may be because aspects of hedonic well-being vary in their relationship to nature affiliation, but also because positive affect can be seen to cover vitality or drive and positive soothing or contentment. They conclude that nature can elicit feelings of ecstasy and wonder, and foster feelings of comfort. Similarly, whilst the main approach in the emotion literature is to apply a categorical approach to the structure of affect, the above highlights the potential benefits of dimensional approaches where experience is much more than a single emotion but felt core affect where importance is placed upon continuums of pleasure and arousal (see for instance Russell 2003).

Moreover, often overlooked is that neurophysiology research has demonstrated two types of positive affect which drive actions that go hand in hand with physiological changes and autonomic support (Fredrickson 2001). The three circle model also indicates two types of positive affect - drive and/ or contentment (Gilbert et al. 2008; Gilbert 2014). Drive is stimulating and activating, accompanied by joy, fun and excitement (high pleasure, high arousal), but is also involved in competitive drives. Drive seeking is linked to the sympathetic nervous system, and over reliance can increase vulnerability to depression, particularly where individuals are striving to achieve in order to avoid inferiority or when individuals experience failures to obtaining a goal (Gilbert et al. 2007, 2009; Gilbert 2014). The second type of positive affect, contentment, affiliation and safeness, can often be overlooked. These calming and soothing emotions (high pleasure, low arousal) are regulating and can bring balance, toning down the sympathetic threat and drive systems. This contentment and affiliation system is linked to the parasympathetic nervous system which is sometimes referred to as the 'rest and digest' arm (Porges 2007) and is associated with opiates and oxytocin. This system is focused on restoration and affiliation and can be compared to a mindful 'being', rather than 'doing' mode - and feeling more 'connected' (Gilbert 2014). As highlighted above, considering positive affect within the context of the three circle model reveals two types of positive affect: one associated with drive and feelings of excitement and the other contentment and feelings of safeness and connectedness.

Beyond Ulrich (1983), a search of the literature that considered terms including natural environment, positive affect, affect regulation and neurophysiology found few papers that considered the neurophysiology of emotion and models of affect regulation within the context of the natural environment. For example, Van den Berg et al. (2003) consider cognitive (e.g. Kaplan 1995) and affective (e.g. Ulrich 1983) processes and provide a useful introduction to affect and restoration with reference to regulation, without moving into neurophysiology beyond mention of physiological indicators of stress. Parsons (1991) considers the influence of the natural environment on well-being within the context of Henry's (1980) model of neuro-endocrine responses and LeDoux's (1998) model of subcortical affective processing. This work supports a proposal for two types of affect initiation response systems within the context of immediate affective responses to environmental stressors. Thus, their approach provides insight into the impact of stressors in urban environments rather than positive affect of natural environments but is rather dated.

Within the context of responses to nature, Ulrich et al. (1991) note that activation of sympathetic nervous system relates to readiness for action, consumes energy and is therefore non-restorative. The parasympathetic system functions to restore and maintain energy and has a central role in attention and restoration. They recognise the need to disentangle the two systems when considering responses to nature.

This entanglement is complex; as suggested above, affective emotions combine valence (positive-neutral-negative) and arousal (activation-inhibition) (Russell 2003; Russell and Barrett 1999). Previously, Watson and Tellegen (1985) also suggested two related dimensions of positive affect: pleasantness and activation. Activation refers to an arousal or engagement continuum including relaxation, through alertness to excitement. Pleasure relates to how well a person is doing and can be viewed from differing conceptual stances, for example positive-negative or approach-avoidance (Russell 2003; Russell and Barrett 1999). Thus, these two proposed dimensions cover similar aspects as the three circle model above, but utilise differing continuums. This and aspects of the discussion above are included in Fig. 2 to provide further context to the three circle model. Affective pleasantness forms part of hedonic well-being, along with a cognitive component related to satisfaction of desires, and this form of well-being is most often considered in nature connection and well-being studies (Capaldi et al. 2014). Hedonic well-being can be seen to include aspects of vitality and contentment, illustrating that the three circle model of affect regulation is a simplification of complex inter-relationships, but nonetheless useful for framing results and explaining the benefits of nature to various stakeholders, many of whom, given the continued focus on the biomedical and neurological basis, welcome reference to underlying physiology when explaining the benefits of nature.

In summary, the three circle model of affect regulation presented provides a new perspective for the well-being benefits of nature, interpretation of results and directions for future research into understanding the benefits we find in nature. We know that nature, and a connection to it, is restorative, bringing the vitality we need in life - but given the role of mindful attention and self-reflection (Richardson and Sheffield 2015), part of the story is about affiliation, soothing and contentment, 


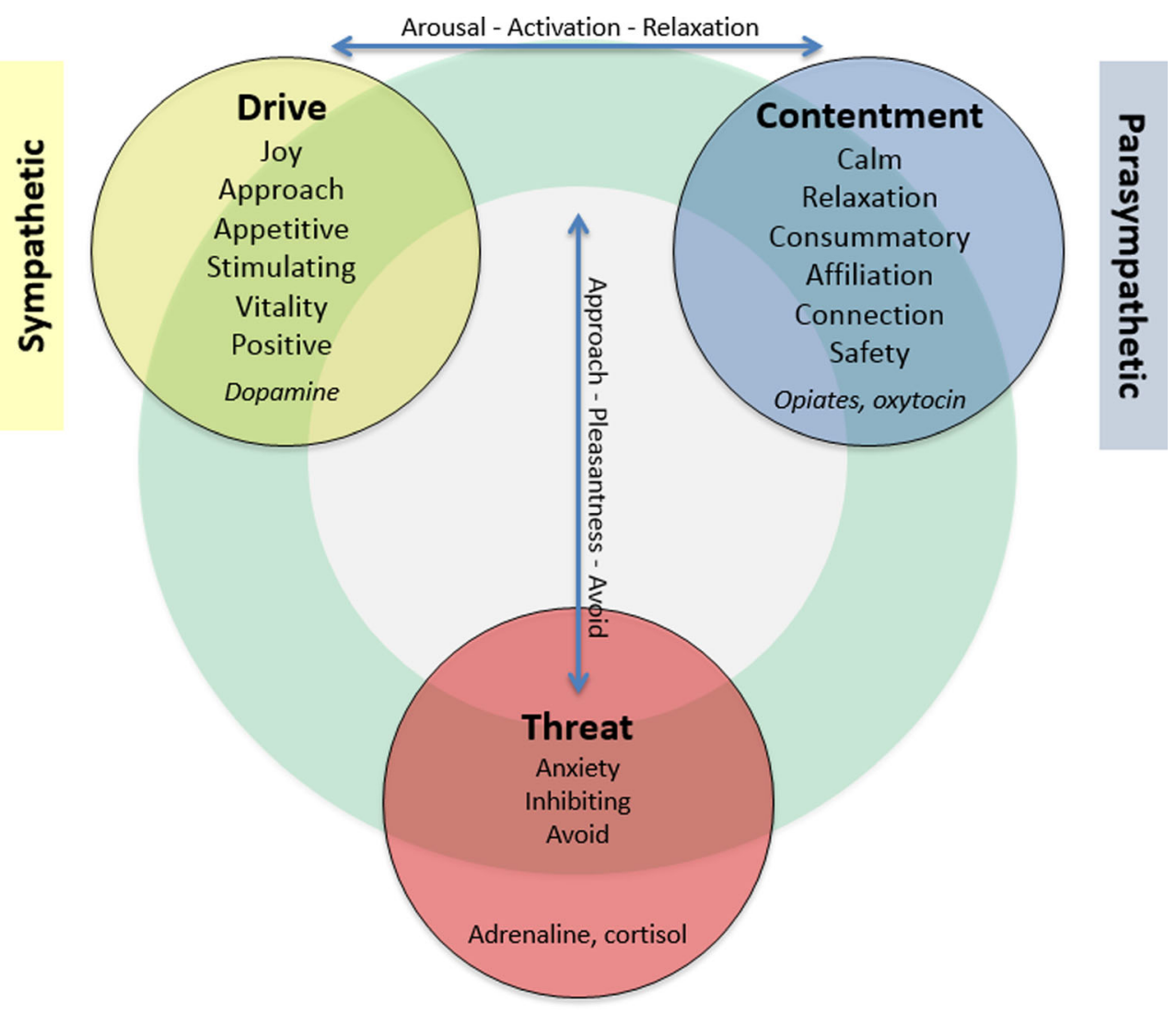

Fig. 2 Three circle model of affect regulation with dimensions of positive affect (informed by Gilbert 2014; Depue and Morrone-Strupinsky 2005; Russell 2003; Watson and Tellegen 1985; Tinbergen 1951)

and explicit assessment of this has often been neglected in previous research.

\section{Sympathetic-Parasympathetic Balance}

Underpinning the affect regulation systems is the physiological systems which bring about these states (of drive, contentment and threat). The sympathetic nervous system is activating and tends to be associated with states of threat or drive; in contrast, the parasympathetic system is inhibitory but restorative and soothing and associated with states of contentment. According to Porges (1995, 2007, 2009), there are two branches of the vagal nerve which feed into the sympathetic and parasympathetic system: one is phylogenetically primitive and therefore unmyelinated. This branch acts as a quick route for stimulation of the sympathetic nervous system in response to threats. The other branch of the vagus nerve feeds into the parasympathetic nervous system, and (in mammals) myelination of the vagus nerve evolved to function as a 'break' to tone-down sympathetic activity (threat and drive), bringing about parasympathetic activity and contentment. This adaptation allowed humans to engage with attachment and affiliative behaviours which are key for social engagement (Porges 2007, 2009) and, crucially, allow more soothing/ affiliative emotion regulation to take place. The balance between these two branches is adaptive and beneficial to health and wellbeing, as it reflects a system that is balanced between threat, drive and contentment, with no single system (e.g. threat) dominating. However, the interplay between these two branches can be complex and produce blended patterns of positive affect (e.g. feeling content but also excited; which is consistent with a dimensional approach to emotion). It is not a simple case because as one system increases the other decreases, nor are the systems mutually exclusive; rather, it is the balance and dynamicity between both systems that produces different physiological and mood states.

One way of investigating the balance between sympathetic and parasympathetic systems, or between drive and contentment, is heart rate variability (HRV). HRV is an established scientific method for indicating changes in the autonomic nervous system, in particular excitatory sympathetic and inhibitory parasympathetic activity that controls the heart. It has been used to study physiological changes related to exposure to nature (Brown et al. 2013; Gladwell et al. 2012). In general, high total HRV indicates good dynamic balance between the sympathetic and parasympathetic system, whereas low total HRV suggests that the sympathetic system dominates. Low HRV is linked to poor health and well-being outcomes (Carney et al. 2005; Thayer et al. 2010). Further, sympathetic mediators, such as threat, appear to exert 
their effects quickly and are reflected in the low-frequency power of the HRV spectrum (Pomeranz et al. 1985). In contrast, vagal mediators, such as contentment, exert their influence more quickly on the heart and principally affect the high-frequency power of the HRV spectrum. Therefore, this review will now consider previous research into the benefits of nature using HRV indicators to demonstrate sympathetic-parasympathetic activity and by association, well-being (and emotions), to nature. The results are tabulated to show the extent to which they concur with the outcomes predicted by the three circle model; specifically, that (i) drive seeking (and threat) is linked to the sympathetic nervous system and will be lower in nature and (ii) contentment is linked to the parasympathetic nervous system and will be higher in nature.

\section{Literature Search and Inclusion Criteria}

A systematic search of the literature (Khan et al. 2003) was used to locate studies for inclusion without any date restrictions. Database searching considered combinations of a number of keywords including natural environment, HRV, physiological, positive affect and affect regulation. The reference sections of relevant papers were studied and citation searches completed in order to widen the search process. This process identified many papers that discuss and review research. Criteria were set to identify those papers that reported primary research into nature exposure whilst measuring HRV in comparison to an urban control. The 14 nature exposure papers that met the inclusion criteria are listed in Table 1 with details of sample size, design and support for the three circle model. A review study that reports a number of primary studies is included. A book chapter and two foreign language studies cited in English language papers were not included as the design or number of participants could not be ascertained.

\section{Meta-analysis}

All analyses were performed using meta-essentials (Van Rhee et al. 2015). Thirteen eligible studies with a total of 871 participants were included in the meta-analysis. First, analyses were conducted and effect sizes calculated for each study (Table 3). Specifically, we calculated $d$ and confidence interval (upper and lower) for studies that examined differences in HRV indicators of parasympathetic activity (rMSSD, HF, lnHF, SD1) and sympatho/parasympathetic balance (LF/HF ratio; $\mathrm{LF} / \mathrm{LF}+\mathrm{HF}$; LF; InLF, SDRR, SD2). Then, for each, a combined effect size was calculated and examined using the Forest plot. Finally, publication bias was examined by calculating the fail safe $N$ (Rosenthal 1979); because fail safe $N$ is biased towards overestimating the number of null studies required to render the overall effect size non-significant (Carson et al. 1990), a funnel plot of the standard error by the standard mean differences was generated.

For parasympathetic activity, the Forest plot revealed a combined effect size of Hedge's $g=0.71$ (CI 0.42 to 0.99 , $p<0.001$, one-tailed) representing a medium effect (Table 2). The overall effect size was somewhat heterogeneous $\left(Q(13)=57.64, p<0.001, I^{2}=79.18\right)$, thus indicating that there are substantial heterogeneity issues, although no study reported effects in the contra-expected direction. Publication bias analyses were undertaken first by calculating fail safe $N$ (Rosenthal 1979). The fail safe $N$ was 157 , suggesting that even if a great number of additional relevant studies with null results were included, the overall effect size would remain significant. The distribution of the funnel plot is symmetrical, suggesting no issues regarding publication bias (see Fig. 3).

For sympatho/parasympathetic balance, the Forest plot revealed a combined effect size of Hedge's $g=0.14(\mathrm{CI}-0.05$ to $0.33, p=0.05$, one-tailed) representing a small effect (Table 3$)$. The overall effect size was somewhat homogeneous $\left(Q(13)=27.24, p<0.001, I^{2}=55.95\right)$, thus indicating that there are some heterogeneity issues. Publication bias analyses were undertaken first by calculating fail safe $N$ (Rosenthal 1979). The fail safe $N$ was 148 . The distribution of the funnel plot is symmetrical, suggesting no issues regarding publication bias (see Fig. 4).

\section{Nature and HRV Research Discussion}

Importantly, the review of each study revealed that they do not consider their results in the context of affect regulation; indeed, many of the studies do not consider affect, having an autonomic nervous system or stress reduction theory (SRT) focus. Many of the studies identified consider forest bathing in Japan (Shinrin-yoku). Although the forest-based studies lack the control of the laboratory, Kappas (2011) is critical of labbased research into emotional response, and McMahan and Estes (2015) found that across 32 studies, there was no significant difference in positive affect responses to real nature vs lab-based nature images/videos. Of the studies identified, all provide full or partial support for the three circle model, with the meta-analysis confirming greater parasympathetic activity and somewhat lower sympathetic activity in the nature exposure conditions compared with the urban control conditions. Partial support occurs where significant differences in sympathetic nervous activity were not found, which is a point of discussion below.

In terms of the three circle model, the vast majority of results show that natural environments promote greater parasympathetic nerve activity (contentment) and lower sympathetic nerve activity (drive) than urban environments, with medium and small effect sizes found in the meta-analyses, 
Table 1 Nature exposure studies that measure HRV

\begin{tabular}{|c|c|c|c|c|c|c|}
\hline Study & Pps & Design & $\begin{array}{l}\text { Greater } \\
\text { parasympathetic }\end{array}$ & $\begin{array}{l}\text { Lower } \\
\text { sympathetic }\end{array}$ & $\begin{array}{l}\text { Supports } \\
\text { three circles }\end{array}$ & Lower anxiety \\
\hline Brown et al. (2013) & 25 & $\begin{array}{l}\text { Lab-based nature vs } \\
\text { urban control }\end{array}$ & Higher than control & Not tested & $\mathrm{P}$ & $\mathrm{n} / \mathrm{a}$ \\
\hline Gladwell et al. (2012) & 29 & $\begin{array}{l}\text { Lab-based nature vs } \\
\text { urban control }\end{array}$ & Higher than control & Not tested & Y & $\mathrm{n} / \mathrm{a}$ \\
\hline Horiuchi et al. (2014) & 15 & $\begin{array}{l}\text { Forest view vs no } \\
\text { view control }\end{array}$ & $\begin{array}{l}\text { Not significant vs control, } \\
\text { but significant effect } \\
\text { of time }\end{array}$ & Not significant & $\mathrm{P}$ & $\mathrm{Y}$ \\
\hline Kobayashi et al. (2015) & 625 & $\begin{array}{l}\text { Forest vs urban } \\
\text { control }\end{array}$ & $80 \%$ higher than control & $64 \%$ lower than control & $\mathrm{Y}$ & $\mathrm{n} / \mathrm{a}$ \\
\hline Lee et al. (2011) & 12 & $\begin{array}{l}\text { Forest vs urban } \\
\text { control }\end{array}$ & Higher than control & Lower than control & Y & $\mathrm{Y}$ \\
\hline Lee et al. (2014) & $40-44$ & $\begin{array}{l}\text { Forest vs urban } \\
\text { control }\end{array}$ & Higher than control & Lower than control & $\mathrm{Y}$ & $\mathrm{Y}$ \\
\hline Lee et al. 2015) & 12 & $\begin{array}{l}\text { Rural vs urban } \\
\text { control }\end{array}$ & Higher than control & Lower than control & $\mathrm{Y}$ & $\mathrm{Y}$ \\
\hline Park et al. 2008) & 12 & $\begin{array}{l}\text { Forest vs urban } \\
\text { control }\end{array}$ & Higher than control & Not significant & $\mathrm{P}$ & $\mathrm{n} / \mathrm{a}$ \\
\hline Park et al. (2009) & 9 & $\begin{array}{l}\text { Forest vs urban } \\
\text { control }\end{array}$ & Higher than control & Lower than control & Y & $\mathrm{n} / \mathrm{a}$ \\
\hline Park et al. (2010) & $\mathrm{n} / \mathrm{a}$ & Review & Higher than control & Lower than control & $\mathrm{Y}$ & $\mathrm{Y}$ \\
\hline Song et al. $(2013 \mathrm{a}, \mathrm{b})$ & 36 & $\begin{array}{l}\text { Forest vs urban } \\
\text { control }\end{array}$ & Higher than control & Not significant & $\mathrm{P}$ & $\mathrm{n} / \mathrm{a}$ \\
\hline Song et al. (2013b) & 13 & $\begin{array}{l}\text { Park vs urban } \\
\text { control }\end{array}$ & Higher than control & Not significant $(p=0.06)$ & $P$ & $\mathrm{Y}$ \\
\hline Song et al. (2015) & 19 & $\begin{array}{l}\text { Lab-based nature vs } \\
\text { urban control }\end{array}$ & Higher than control & Not significant & $\mathrm{P}$ & $\mathrm{Y}$ \\
\hline Tsunetsugu et al. (2007) & $5-12$ & $\begin{array}{l}\text { Forest vs urban } \\
\text { control }\end{array}$ & $\begin{array}{l}\text { Higher at selected time } \\
\text { points }\end{array}$ & Lower than control & Y & $\mathrm{n} / \mathrm{a}$ \\
\hline Tsunetsugu et al. (2013) & $41-44$ & $\begin{array}{l}\text { Forest vs urban } \\
\text { control }\end{array}$ & $\begin{array}{l}\text { Higher at selected time } \\
\text { points }\end{array}$ & Lower than control & $\mathrm{Y}$ & $\mathrm{Y}$ \\
\hline
\end{tabular}

Results support etc.: $Y$ yes, $P$ partial, $N$ no

respectively. An issue in the current context with such comparison to control studies is the observation that HRV in nature could remain the same, with urban environments stimulating sympathetic activity. It could then be argued that changes within the urban environments are actually responsible for the production of significant differences. Of importance here however, whilst few of the included studies consider temporal analysis, three studies do indicate within-group temporal changes for components of HRV (Tsunetsugu et al. 2007; Song et al. 2015; Lee et al. 2014). The excluded book chapter also reported significant differences in changes in HRV (Lee et al. 2012). Therefore, there can be confidence that it is in fact nature bringing benefits, rather than urban environments removing them.

Recent results by Kobayashi et al. (2015) reveal interesting detail. Mirroring the medium and small effect sizes found in the meta-analysis, they noted that approximately $80 \%$ of participants showed an increase in the parasympathetic indicator of HRV, and $64 \%$ showed decreases in the sympathetic indicator of HRV; the remaining participants showed opposite responses. This raises the question as to the role of threat, anxiety and phobias in natural environments (e.g. some environments contain features which may have been a threat to survival in our evolutionary history). Certainly, it is known that evolution has provided us with a set of 'primed' emotional responses which result in rapid selective learning and great difficulty in extinguishing such responses (see for example the seminal work of Mineka et al. 1984). Not surprisingly, therefore, Kobayashi et al. (2015) note that some people with biophobia (Kellert 1993) report a strong dislike for natural environments, and this includes specific phobias such as arachnophobia. People with arachnophobia showed increased heart rate during presentation of images or thoughts of spiders.

It can further be seen that eight of the studies measured anxiety, most often using POMS, all finding lower anxiety in the natural environment. However, those studies did not report analysis on anxiety as a potential barrier to positive HRV changes which may prove essential for our further understanding of the relationship between nature and positive emotions (especially given selective learning of primed emotions). Further, the three circle model presented, albeit simple, extends a number of emotion regulation models that have 
Table 2 Parasympathetic studies

\begin{tabular}{lllll}
\hline Study name & Hedges' $g$ & $\begin{array}{l}\text { CI Lower } \\
\text { limit }\end{array}$ & $\begin{array}{l}\text { CI upper } \\
\text { limit }\end{array}$ & Weight (\%) \\
\hline Brown et al. (2013) & 0.57 & 0.14 & 1 & 8.54 \\
Gladwell et al. (2012) & 0.24 & -0.13 & 0.62 & 9.08 \\
Horiuchi et al. (2014) & 0.22 & -0.3 & 0.75 & 7.79 \\
Kobayashi et al. (2015) & 0.97 & 0.87 & 1.06 & 11.21 \\
Lee et al. (2011) & 0.65 & -0.12 & 1.42 & 6.16 \\
Lee et al. (2014) & 0.47 & 0.14 & 0.8 & 9.47 \\
Lee et al. (2015) & 1.17 & 0.38 & 1.95 & 5.77 \\
Park et al. (2008) & 0.59 & -0.05 & 1.23 & 6.90 \\
Park et al. (2009) & 0.63 & -0.09 & 1.35 & 6.43 \\
Song et al. (2013a, b) & 1.48 & 0.82 & 2.15 & 6.44 \\
Song et al. (2013b) & 0.63 & 0.01 & 1.26 & 7.02 \\
Song et al. (2015) & 1.92 & 1.14 & 2.69 & 5.56 \\
Tsunetsugu et al. (2013) & 0.3 & -0.01 & 0.62 & 9.61 \\
\hline
\end{tabular}

come before it, by including physiological indices of sympathetic activity and indicating that such activity can also be linked to stimulation, joy and excitement. Therefore, there is the potential for increased sympathetic activity, rather than a decrease, in more connected individuals who report increased vitality in nature (Capaldi et al. 2014). Finally, the approach to sympathetic-related measures varied considerably. These confounding factors could lead to the smaller differences in the sympathetic measurements, which achieved one-tailed significance with a smaller effect size in the meta-analysis.

Subsequently, there is a need for further consideration of individual differences and physiological responses. People who are more connected with nature experience greater psychological benefits from contact with nature (Hartig et al.
2011). Mindful attention and self-reflection are two further aspects associated with greater connection to nature (Richardson and Sheffield 2015). Further, it has been shown that spirituality (Kamitsis and Francis 2013) and engagement with natural beauty (Zhang et al. 2014) are involved in the relationship between nature connectedness and well-being. It is worth noting that Berridge (2009) proposes that positive emotions may use sensory pleasure circuits, bringing about a link between aesthetic enjoyment and positive consummatory states (Kappas 2011). Whilst the idea of pleasure circuits is not new and has been briefly reviewed prior to the presentation of the three circle model, this could well explain Zhang's finding that engaging with nature's beauty was required for well-being benefits. Last but not least, there may also be
Fig. 3 Funnel plot of standard error by standard differences in the means of parasympathetic measures

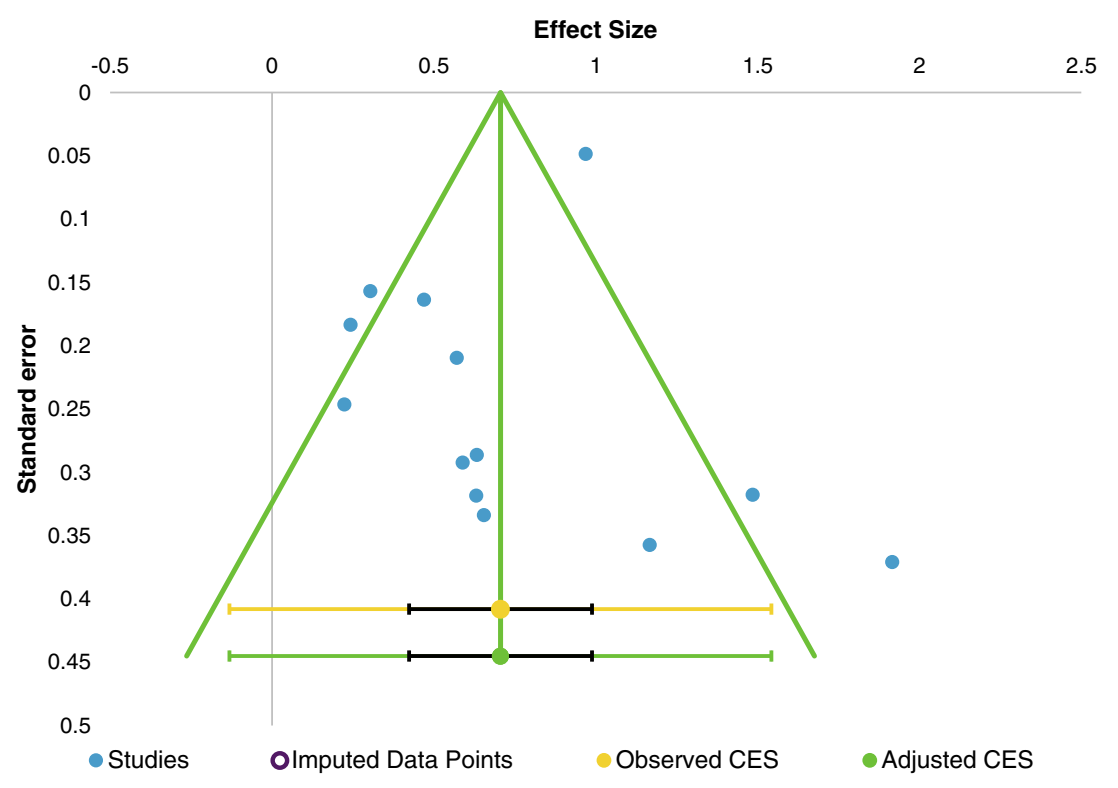


Table 3 Sympatheticparasympathetic balance studies

\begin{tabular}{lllll}
\hline Study name & Hedges' $g$ & $\begin{array}{l}\text { CI lower } \\
\text { limit }\end{array}$ & $\begin{array}{l}\text { CI upper } \\
\text { limit }\end{array}$ & Weight (\%) \\
\hline Brown et al. (2013) & 0 & -0.4 & 0.4 & 8.35 \\
Gladwell et al. (2012) & 0.25 & -0.12 & 0.63 & 8.80 \\
Horiuchi et al. (2014) & 0.22 & -0.3 & 0.75 & 6.34 \\
Kobayashi et al. (2015) & 0.32 & 0.24 & 0.4 & 16.33 \\
Lee et al. (2011) & 0 & -0.68 & 0.68 & 4.95 \\
Lee et al. (2014) & 0.44 & 0.11 & 0.76 & 9.83 \\
Lee et al. (2015) & -0.98 & -1.72 & -0.25 & 4.16 \\
Park et al. (2008) & 0 & -0.59 & 0.59 & 5.73 \\
Park et al. (2009) & 0.63 & -0.09 & 1.35 & 4.46 \\
Song et al. (2013a, b) & 0 & -0.45 & 0.45 & 7.49 \\
Song et al. (2013b) & 0.31 & -0.26 & 0.89 & 5.76 \\
Song et al. (2015) & 0 & -0.45 & 0.45 & 7.49 \\
Tsunetsugu et al. (2013) & 0.03 & -0.28 & 0.34 & 10.32 \\
\hline
\end{tabular}

differences in those who come from rural or urban environments, differences based on individual's motivations for visiting green spaces (e.g. rest and relaxation, adventure, challenge, work) and what activities they engage in there. This could all influence the blend of emotions derived from being in nature and attests to the importance of dimensional approaches when considering emotions in nature. None of the studies in the meta-analysis explicitly explore these factors. Here therefore we are in agreement with Van den Berg et al. (2003) who argue that more research taking in different scenarios, different types of green and blue settings and different groups of participants is needed to gain further understanding of the physiological and psychological pathways between natural spaces and well-being.
In sum, the three circle model provides a framework for considering the benefits of nature and provides direction for further research. It is drawn from preceding emotion regulation literature and has been shown to fit with literature on a dimensional approach to emotion and positive affect. Albeit presented here in a simplified accessible format, there is scope for the model to explain the varying HRV results by considering the role of anxiety in reducing benefits. Further, nature connectedness mediates the well-being benefits of nature (Richardson et al. 2016) and will therefore mediate the benefits revealed by HRV measurements. Finally, engagement with natural beauty, self-reflection and mindful attention may also explain the differences in individuals' response to natural
Fig. 4 Funnel plot of standard error by standard differences in the means of sympatheticparasympathetic balance measures

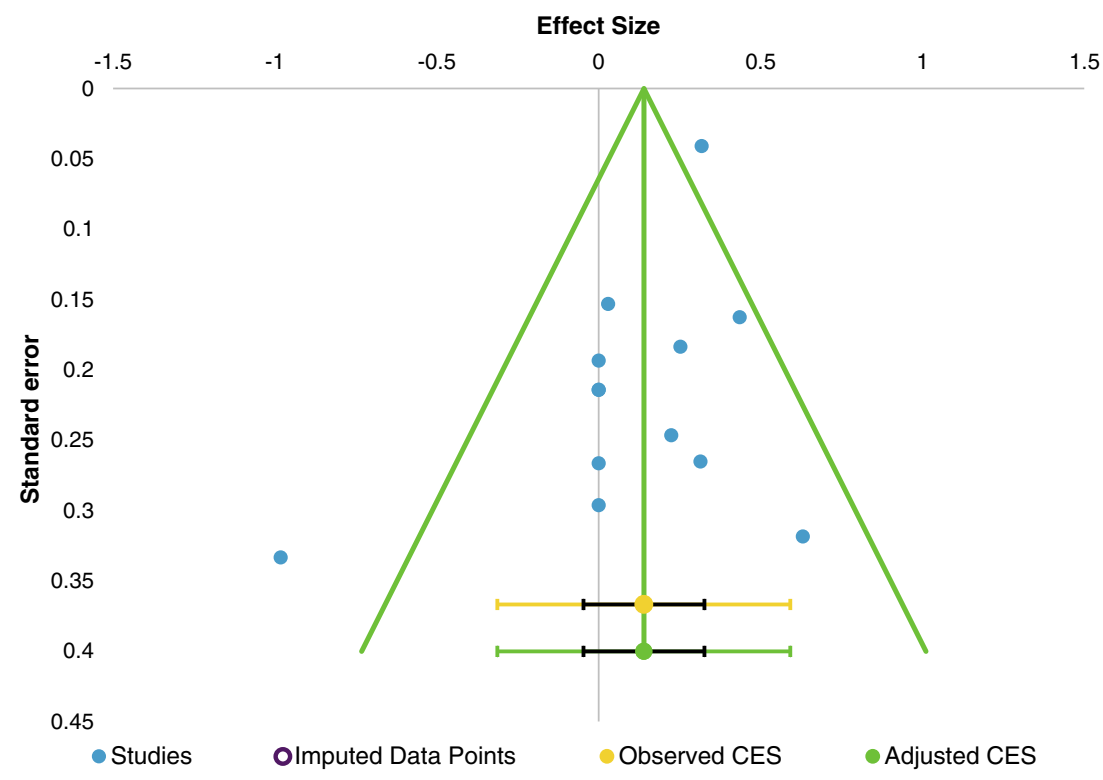


environments, but can all be accounted for in terms of the three circle model.

\section{Conclusions}

The purpose of this brief review was to highlight the need to link emotional responses to affect regulation (Kappas 2011) and present evidence to support the application of an existing and accessible evolutionary functional three circle model of emotion and affect regulation within the context of the wellbeing benefits of nature. A key outcome of this process is the reminder to focus on the two types of positive affect that can explain previous mixed results (Howell and Passmore 2013), as well as consider a dimensional approach to emotion in nature.

It is also possible to consider previous nature and wellbeing research using subjective measures within the context of the three circle model. A further review of the nature and well-being literature placing it into the context of the model is beyond the scope of the current review which focusses on proposing and evidencing the three circle model with relevant HRV studies. Therefore, examples broadly considering the three main aspects of the model, including the two types of positive affect, are used to illustrate its wider utility. For example, there has been a body of research that considers positive outcomes of nature engagement, such as improved vitality (Capaldi et al. 2014). This body of work can be mapped onto the drive aspect within the context of stimulation, joy and high arousal/high pleasure. In contrast, work on mindful attention and reflection (e.g. Richardson and Sheffield 2015; Howell et al. 2011) can be mapped onto the contentment aspect within the context of calm and low arousal/high pleasure. Finally, barriers to nature such as rumination and neuroticism (Richardson and Sheffield 2015) as well as potential selectively learnt anxieties can be mapped onto the threat dimension.

The model can also be considered within the context of existing theories regarding the benefits of nature. Psychoevolutionary SRT focuses on restoration after stress (Ulrich et al. 1991). SRT suggests increased positive affect, with the three circle model highlighting the need to consider both contentment and drive. The model can also be seen to include physiological arousal based on physiological adaptation to natural environments. Further, Mantler and Logan (2015) note that emotion is central to SRT; hence, following Kappas (2011), there is a need to consider affect regulation.

The attention restoration theory (ART) (Kaplan 1995) focusses on directed attention which requires non-salient distracters to be ignored, which brings cognitive effort. Directed attention, which can be compared to drive and sometimes threat, is common in modern life and ART proposes that natural environments are restorative. Its soft fascination provides involuntary attention which facilities calm, rest and contemplation (Beute and Kort 2014), thereby bringing the desired balance between the three aspects of the three circle affect regulation model.

ART and SRT are both based on restoration, but Beute and Kort (2014) used HRV as an indicator of exertion of selfcontrol and challenged the proposition that nature primarily provides restorative benefits, as results showed beneficial effects of nature when resources had not been depleted. The three circle model of affect regulation supports this account and encourages a perspective of wellness through balance. Nature can bring both joy and excitement and contentment and affiliation. Both are argued to bring a balanced emotional state and it is known that imbalance can lead to affective disorders (e.g. mania is associated with excessive drive, arousal and extreme euphoria). In terms of general well-being, the model allows for nature to be restorative and reduce stressors, whilst also highlighting that natural environments may not feel safe to some.

The three circle model also provides a tested framework in which to consider positive affect and the mental well-being and the benefits of nature. For example, stimulation of our contentment system is a goal of psychological therapies such as compassion-focused therapy. If natural environments can be used to stimulate this type of positive affect regulation system, nature can potentially be used to tone-down the threat system and bring about positive physiological change in the body. This would improve parasympathetic-sympathetic balance as indicated by the HRV literature above. Adding support for this argument, it is now well recognised that exercises used within CFT influence brain and bodily responding (see for example Duarte et al. 2015; Longe et al. 2010).

Finally, the three circle model can be easily understood in the context of our everyday lives and the model is accessible to all. Crucially, the model in its present state provides a narrative for the lay person to understand the benefits of nature whilst providing a convincing physiological basis for those not convinced by more subjective emotional accounts.

\section{References}

Averbeck, B. B., \& Seo, M. (2008). The statistical neuroanatomy of frontal networks in the macaque. PLoS Computational Biology, 4(4), e1000050.

Berridge, K. C. (2009). Wanting and liking: observations from the neuroscience and psychology laboratory. Inquiry, 52(4), 378-398.

Beute, F., \& Kort, Y. A. (2014). Salutogenic effects of the environment: review of health protective effects of nature and daylight. Applied Psychology: Health and Well-Being, 6(1), 67-95.

Bressan, R. A., \& Crippa, J. A. (2005). The role of dopamine in reward and pleasure behaviour-review of data from preclinical research. Acta Psychiatrica Scandinavica, 111(s427), 14-21. 
Brown, D. K., Barton, J. L., \& Gladwell, V. F. (2013). Viewing nature scenes positively affects recovery of autonomic function following acute-mental stress. Environmental Science \& Technology, 47(11), $5562-5569$.

Capaldi, C. A., Dopko, R. L., \& Zelenski, J. M. (2014). The relationship between nature connectedness and happiness: a meta-analysis. Frontiers in Psychology, 5, 976.

Carney, R. M., Blumenthal, J. A., Freedland, K. E., Stein, P. K., Howells, W. B., Berkman, L. F., Watkins, L. L., Czajkowski, S. M., Hayano, J., Domitrovich, P. P., \& Jaffe, A. S. (2005). Low heart rate variability and the effect of depression on post-myocardial infarction mortality. Archives of Internal Medicine, 165(13), 1486-1491. doi:10.1001/archinte.165.13.1486.

Carson, K. P., Schriesheim, C. A., \& Kinicki, A. J. (1990). The usefulness of the "fail-safe" statistic in meta-analysis. Educational and Psychological Measurement, 50(2), 233-243.

Cho, M. M., DeVries, A. C., Williams, J. R., \& Carter, C. S. (1999). The effects of oxytocin and vasopressin on partner preferences in male and female prairie voles (Microtus ochrogaster). Behavioral Neuroscience, 113(5), 1071.

Darwin, C. (1872). 1965. The expressions of the emotions in man and animals. Chicago: The University of Chicago Press.

de Almeida, J. R. C., Versace, A., Mechelli, A., Hassel, S., Quevedo, K., Kupfer, D. J., \& Phillips, M. L. (2009). Abnormal amygdalaprefrontal effective connectivity to happy faces differentiates bipolar from major depression. Biological Psychiatry, 66(5), 451-459.

Depue, R. A., \& Morrone-Strupinsky, J. V. (2005). A neurobehavioral model of affiliative bonding. Behavioral and Brain Sciences, 28, 313-395.

Duarte, J., McEwan, K., Barnes, C., Gilbert, P., \& Maratos, F. A. (2015). Do therapeutic imagery practices affect physiological and emotional indicators of threat in high self-critics? Psychology and Psychotherapy: Theory, Research and Practice, 88(3), 270-284.

Etkin, A. (2009). Functional neuroanatomy of anxiety: a neural circuit perspective. In Behavioral neurobiology of anxiety and its treatment (pp. 251-277). Berlin: Springer.

Etkin, A., Büchel, C., \& Gross, J. J. (2015). The neural bases of emotion regulation. Nature Reviews Neuroscience, 16(11), 693-700.

Fox, A. S., Oler, J. A., Tromp, D. P., Fudge, J. L., \& Kalin, N. H. (2015). Extending the amygdala in theories of threat processing. Trends in Neurosciences, 38(5), 319-329.

Fredrickson, B. L. (2001). The role of positive emotions in positive psychology: the broaden-and-build theory of positive emotions. American Psychologist, 56(3), 218.

Frijda, N. H. (1987). Emotion, cognitive structure, and action tendency. Cognition and Emotion, 1(2), 115-143.

Park, B. J., Tsunetsugu, Y., Hirano, H., Kagawa, T., \& Miyazaki, Y. (2007). Physiological evaluation of the effects of Shinrinyoku (taking in the atmosphere of the forest) in Kayanodaira Highland, Kijimadaira Village, Nagano Prefecture (in Japanese). Kanto Journal of Forest Research, 58, 219-222.

Jones, M. V., Hurst, G., Masterson, D., Clark-Carter, D., Tarvainen, M. P., Smith, G., \& Nieuwenhuijsen, M. (2015). Where to put your best foot forward: psycho-physiological responses to walking in natural and urban environments. Journal of Environmental Psychology. doi:10.1016/j.jenvp.2015.11.003.

Gilbert, P. (2005). Compassion: conceptualisations, research and use in psychotherapy. Oxford: Routledge.

Gilbert, P. (2009a). The compassionate mind: a new approach to the challenges of life. London: Constable \& Robinson.

Gilbert, P. (2009b). Introducing compassion-focused therapy. Advances in Psychiatric Treatment, 15(3), 199-208.

Gilbert, P. (2014). The origins and nature of compassion focused therapy. British Journal of Clinical Psychology, 53(1), 6-41.

Gilbert, P., Broomhead, C., Irons, C., McEwan, K., Bellew, R., Mills, A., \& Gale, C. (2007). Striving to avoid inferiority: scale development and its relationship to depression, anxiety and stress. British Journal of Social Psychology, 46, 633-648.

Gilbert, P., McEwan, K., Mitra, R., Franks, L., Richter, A., \& Rockliff, H. (2008). Feeling safe and content: a specific affect regulation system? Relationship to depression, anxiety, stress, and self-criticism. The Journal of Positive Psychology, 3(3), 182-191.

Gilbert, P., McEwan, K., Bellew, R., Mills, A., \& Gale, C. (2009). The dark side of competition: how competitive behaviour and striving to avoid inferiority are linked to depression, anxiety, stress and self harm. Psychology and Psychotherapy: Theory, Research and Practice, 82, 123-136.

Gladwell, V. F., Brown, D. K., Barton, J. L., Tarvainen, M. P., Kuoppa, P., Pretty, J., Suddaby, J. M., \& Sandercock, G. R. H. (2012). The effects of views of nature on autonomic control. European Journal of Applied Physiology, 112(9), 3379-3386.

Graustella, A. J., \& MacLeod, C. (2012). A critical review of the influence of oxytocin nasal spray on social cognition in humans: evidence and future directions. Hormones and Behavior, 61(3), 410 418.

Gray, J. A. (1982). On mapping anxiety. Behavioral and Brain Sciences, $5(03), 506-534$.

Hartig, T., van den Berg, A. E., Hagerhall, C. M., Tomalak, M., Bauer, N., Hansmann, R., Ojala, A., Syngollitou, E., Carrus, G., van Herzele, A., \& Bell, S. (2011). Health benefits of nature experience: psychological, social and cultural processes. In K. Nilsson, M. Sangster, C. Gallis, K. De Vries, K. Seeland, \& J. Schipperijn (Eds.), Forests, trees and human health (pp. 127-168). New York: Springer.

Henry, J. P. (1980). Present concept of stress theory. In E. Ursdin, R. Kvetnansky, \& I. J. Kopin (Eds.), Catecholamines and stress: recent advances (pp. 557-571). New York: Elsevier.

Horiuchi, M., Endo, J., Takayama, N., Murase, K., Nishiyama, N., Saito, H., \& Fujiwara, A. (2014). Impact of viewing vs. not viewing a real forest on physiological and psychological responses in the same setting. International Journal of Environmental Research and Public Health, 11(10), 10883-10901.

Howell, A. J., \& Passmore, H. A. (2013). The nature of happiness: nature affiliation and mental well-being. In C. L. M. Keyes (Ed.), Mental well-being (pp. 231-257). New York: Springer.

Howell, A. J., Dopko, R. L., Passmore, H. A., \& Buro, K. (2011). Nature connectedness: associations with well-being and mindfulness. Personality and Individual Differences, 51(2), 166-171.

Kamitsis, I., \& Francis, A. J. (2013). Spirituality mediates the relationship between engagement with nature and psychological wellbeing. Journal of Environmental Psychology, 36, 136-143.

Kaplan, S. (1995). The restorative benefits of nature: toward an integrative framework. Journal of Environmental Psychology, 15(3), 169182.

Kappas, A. (2011). Emotion and regulation are one! Emotion Review, $3(1), 17-25$.

Kellert, S. R. (1993). The biological basis for human values of nature. In S. R. Kellert \& E. O. Wilson (Eds.), The biophilia hypothesis (pp. 42-69). Washington: Island Press.

Khan, K. S., Kunz, R., Kleijnen, J., \& Antes, G. (2003). Five steps to conducting a systematic review. Journal of the Royal Society of Medicine, 96(3), 118-121.

Kobayashi, H., Song, C., Ikei, H., Kagawa, T., \& Miyazaki, Y. (2015). Analysis of individual variations in autonomic responses to urban and forest environments. Evidence-Based Complementary and Alternative Medicine, 2015.

LeDoux, J. (1998). The emotional brain. London: Weidenfeld and Nicolson.

LeDoux, J. E. (2014). Coming to terms with fear. Proceedings of the National Academy of Sciences, 111(8), 2871-2878.

Lee, J., Park, B. J., Tsunetsugu, Y., Ohira, T., Kagawa, T., \& Miyazaki, Y. (2011). Effect of forest bathing on physiological and psychological 
responses in young Japanese male subjects. Public Health, 125(2), 93-100.

Lee, J., Park, B. J., Tyrväinen, L., Li, Q., Kagawa, T., Miyazaki, Y., \& Tsunetsugu, Y. (2012). Nature therapy and preventive medicine. INTECH Open Access Publisher.

Lee, J., Tsunetsugu, Y., Takayama, N., Park, B. J., Li, Q., Song, C., \& Miyazaki, Y. (2014). Influence of forest therapy on cardiovascular relaxation in young adults. Evidence-Based Complementary and Alternative Medicine, 69(2), 104-110.

Lee, J., Park, B. J., Ohira, T., Kagawa, T., \& Miyazaki, Y. (2015). Acute effects of exposure to a traditional rural environment on urban dwellers: a crossover field study in terraced farmland. International Journal of Environmental Research and Public Health, 12(2), 1874-1893.

Leknes, S., \& Tracey, I. (2008). A common neurobiology for pain and pleasure. Nature Reviews Neuroscience, 9(4), 314-320.

Lindquist, K. A., Wager, T. D., Kober, H., Bliss-Moreau, E., \& Barrett, L. F. (2012). The brain basis of emotion: a meta-analytic review. Behavioral and Brain Sciences, 35(03), 121-143.

Longe, O., Maratos, F. A., Gilbert, P., Evans, G., Volker, F., Rockliff, H., \& Rippon, G. (2010). Having a word with yourself: neural correlates of self-criticism and self-reassurance. NeuroImage, 49(2), 18491856.

MacLean, P. D. (1949). Psychosomatic disease and the "visceral brain": recent developments bearing on the Papez theory of emotion. Psychosomatic Medicine, 11(6), 338-353.

MacLean, P. D. (1990). The triune brain in evolution: role in paleocerebral functions. New York: Plenum.

Mantler, A., \& Logan, A. C. (2015). Natural environments and mental health. Advances in Integrative Medicine, 2(1), 5-12.

Maratos, F. A., Mogg, K., Bradley, B. P., Rippon, G., \& Senior, C. (2009). Coarse threat images reveal theta oscillations in the amygdala: a magnetoencephalography study. Cognitive, Affective, \& Behavioral Neuroscience, 9(2), 133-143.

McMahan, E. A., \& Estes, D. (2015). The effect of contact with natural environments on positive and negative affect: a meta-analysis. The Journal of Positive Psychology, 10(6), 507-519.

Méndez-Bértolo, C., Moratti, S., Toledano, R., Lopez-Sosa, F., MartínezAlvarez, R., Mah, Y. H., ... \& Strange, B. A. (2016). A fast pathway for fear in human amygdala. Nature Neuroscience.

Mineka, S., Davidson, M., Cook, M., \& Keir, R. (1984). Observational conditioning of snake fear in rhesus monkeys. Journal of Abnormal Psychology, 93(4), 355.

Nave, G., Camerer, C., \& McCullough, M. (2015). Does oxytocin increase trust in humans? A critical review of research. Perspectives on Psychological Science, 10(6), 772-789.

Netmums (2016). CMA: the three circles model. Retrieved from: www. netmums.com/woman/health-and-happiness/making-mumshappy/cma-the-three-circles-model.

Ochsner, K. N., Silvers, J. A., \& Buhle, J. T. (2012). Functional imaging studies of emotion regulation: a synthetic review and evolving model of the cognitive control of emotion. Annals of the New York Academy of Sciences, 1251(1), E1-E24.

Olds, J. (1956). Pleasure centers in the brain. Scientific American, 195, $105-117$.

Panksepp, J. (1998a). Affective neuroscience. New York: Oxford University Press.

Panksepp, J. (1998b). Affective neuroscience: the foundations of human and animal emotions. Oxford: Oxford University Press.

Papez, J. W. (1937). A proposed mechanism of emotion. Archives of Neurology \& Psychiatry, 38(4), 725-743.

Park, B. J., Tsunetsugu, Y., Ishii, H., Furuhashi, S., Hirano, H., Kagawa, T., \& Miyazaki, Y. (2008). Physiological effects of Shinrin-yoku (taking in the atmosphere of the forest) in a mixed forest in Shinano Town, Japan. Scandinavian Journal of Forest Research, 23(3), 278-283.
Park, B. J., Tsunetsugu, Y., Kasetani, T., Morikawa, T., Kagawa, T., \& Miyazaki, Y. (2009). Physiological effects of forest recreation in a young conifer forest in Hinokage Town, Japan. Silva Fennica, 43(2), 291-301.

Park, B. J., Tsunetsugu, Y., Kasetani, T., Kagawa, T., \& Miyazaki, Y. (2010). The physiological effects of Shinrin-yoku (taking in the forest atmosphere or forest bathing): evidence from field experiments in 24 forests across Japan. Environmental Health and Preventive Medicine, 15(1), 18-26.

Parsons, R. (1991). The potential influences of environmental perception on human health. Journal of Environmental Psychology, 11(1), 123.

Pedersen, C. A., Caldwell, J. D., Walker, C., Ayers, G., \& Mason, G. A. (1994). Oxytocin activates the postpartum onset of rat maternal behavior in the ventral tegmental and medial preoptic areas. Behavioral Neuroscience, 108(6), 1163.

Pessoa, L. (2014). Understanding brain networks and brain organization. Physics of Life Reviews, 11(3), 400-435.

Phelps, E. A., \& Ledoux, J. E. (2005). Contributions of the amygdala to emotion processing: from animal models to human behavior. Neuron, 48, 175-187.

Pomeranz, B., Macaulay, R. J., Caudill, M. A., Kutz, I., Adam, D., Gordon, K. M., Kilborn, A. C., Barger, D. C., Shannon, Cohen, R. J., \& Benson, H. (1985). Assessment of autonomic function in humans by heart rate spectral analysis. American Journal of Physiology-Heart and Circulatory Physiology, 248(1), H151H153.

Porges, S. W. (1995). Orienting in a defensive world: mammalian modifications of our evolutionary heritage: a polyvagal theory. Psychophysiology, 32, 301-318.

Porges, S. W. (2007). The polyvagal perspective. Biological Psychology, 74(2), 116-143.

Porges, S. W. (2009). The polyvagal theory: new insights into adaptive reactions of the autonomic nervous system. Cleveland Clinic Journal of Medicine, 76(Suppl 2), S86.

Richardson, M., \& Sheffield, D. (2015). Reflective self-a ention: A more stable predictor of connection to nature than mindful attention. Ecopsychology, 7(30),166-175.

Richardson, M., Cormack, A., McRobert, L., \& Underhill, R. (2016). 30 days wild: development and evaluation of a large-scale nature engagement campaign to improve well-being. PLoS ONE, 11(2), e0149777. doi:10.1371/journal.pone.0149777.

Rosenthal, R. (1979). The file drawer problem and tolerance for null results. Psychological Bulletin, 86(3), 638.

Russell, J. A. (2003). Core affect and the psychological construction of emotion. Psychological Review, 110(1), 145.

Russell, J. A., \& Barrett, L. F. (1999). Core affect, prototypical emotional episodes, and other things called emotion: dissecting the elephant. Journal of Personality and Social Psychology, 76(5), 805.

Song, C., Ikei, H., Tsunetsugu, Y., Lee, J., Kagawa, T., \& Miyazaki, Y. (2013a). Physiological and psychological impacts of walking stress in an urban environment on young males. Journal of Geography and Natural Disasters, 3, 113.

Song, C., Joung, D., Ikei, H., Igarashi, M., Aga, M., Park, B. J., ... \& Miyazaki, Y. (2013). Physiological and psychological effects of walking on young males in urban parks in winter. Journal of Physiological Anthropology, 32(1), 1.

Song, C., Ikei, H., Kobayashi, M., Miura, T., Taue, M., Kagawa, T., Li, Q., Kumeda, S., Imai, M., \& Miyazaki, Y. (2015). Effect of forest walking on autonomic nervous system activity in middle-aged hypertensive individuals: a pilot study. International Journal of Environmental Research and Public Health, 12(3), 2687-2699.

Thayer, J. F., Yamamoto, S. S., \& Brosschot, J. F. (2010). The relationship of autonomic imbalance, heart rate variability and cardiovascular disease risk factors. International Journal of Cardiology, 141(2), 122-131. doi:10.1016/j.ijcard.2009.09.543. 
Tinbergen, N. (1951). The study of instinct. New York: Oxford University Press.

Tsunetsugu, Y., Park, B. J., Ishii, H., Hirano, H., Kagawa, T., \& Miyazaki, Y. (2007). Physiological effects of Shinrin-yoku (taking in the atmosphere of the forest) in an old-growth broadleaf forest in Yamagata Prefecture, Japan. Journal of Physiological Anthropology, 26(2), 135-142.

Tsunetsugu, Y., Lee, J., Park, B. J., Tyrväinen, L., Kagawa, T., \& Miyazaki, Y. (2013). Physiological and psychological effects of viewing urban forest landscapes assessed by multiple measurements. Landscape and Urban Planning, 113, 90-93.

Ulrich, R. S. (1983). Aesthetic and affective response to natural environment. In I. Altman \& J. Wohlwill (Eds.), Behavior and the natural environment (pp. 85-125). New York: Plenum.

Ulrich, R. S., Simons, R. F., Losito, B. D., Fiorito, E., Miles, M. A., \& Zelson, M. (1991). Stress recovery during exposure to natural and urban environments. Journal of Environmental Psychology, 11(3), 201-230.
Van den Berg, A. E., Koole, S. L., \& van der Wulp, N. Y. (2003). Environmental preference and restoration: (how) are they related? Journal of Environmental Psychology, 23(2), 135-146.

Van Rhee, H. J., Suurmond, R., \& Hak, T. (2015). User manual for metaessentials: workbooks for meta-analysis (version 1.0). Rotterdam: Erasmus Research Institute of Management. Retrieved from www. erim.eur.nl/research-support/meta-essentials.

Watson, D., \& Tellegen, A. (1985). Toward a consensual structure of mood. Psychological Bulletin, 98(2), 219.

Wilson, E. O. (1984). Biophilia. Cambridge: Harvard University Press.

Wilson, E. O. (1992). The diversity of life. London: Penguin.

Zhang, J. W., Howell, R. T., \& Iyer, R. (2014). Engagement with natural beauty moderates the positive relation between connectedness with nature and psychological well-being. Journal of Environmental Psychology, 38, 55-63. 